\title{
Processing, Microstructure and High Strain Rate Behaviour of Ti-6Al-4V Alloy Produced From a Blended Mixture Using Powder Compact Extrusion
}

\author{
Ajit Pal Singh ${ }^{a}{ }^{*}$, Brian Gabbitas ${ }^{\mathrm{b}}$, Fei Yang $^{\mathrm{c}}$ and Rob Torrens \\ Waikato Centre for Advance Materials, School of Engineering, University of Waikato, Hamilton, \\ New Zealand

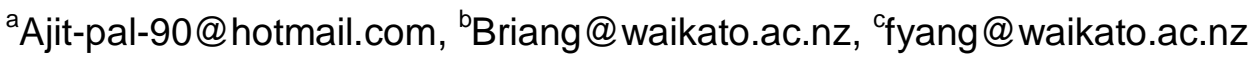

Keywords: Blended powder metallurgy, Ti-6Al-4V alloy, impurity oxygen, micro-cracking, impact toughness, fracture behavior

\begin{abstract}
Powder compact extrusion (PCE) is an innovative way of processing titanium and titanium alloys to produce good-quality material with a wide range of compositions, microstructures and mechanical properties. This paper explores PCE processing of Ti-6Al-4V alloy prepared from a blended powder mixture, containing elemental hydride-dehydride (HDH) titanium powder and master alloy (60Al$40 \mathrm{~V})$ powder. The warm pressed compacts of blended powders were sintered using a vacuum sintering furnace prior to $\beta$ extrusion. The resulting material was used to measure the performance under high strain rate and tri-axial stress state using Charpy v-notch testing. A comparison was made of the microstructure after vacuum sintering and hot extrusion in addition to oxygen measurements to determine the degree of oxygen pickup during each processing stage. A comprehensive study of fracture surfaces in selected samples was carried out using optical microscopy and scanning electron microscopy. Based on the results, it is clear that certain samples picked up varying amounts of interstitial impurities during processing and as a consequence a significant number of micro-cracks were observed in lamellar type microstructures. The oxygen content of all as-extruded samples was between 0.34-0.44 wt.\% with resultant impact toughness in the range of 10-14 J. The best impact toughness attained for the lowest oxygen as-extruded rods was $20 \%$ lower than the literature values for wrought material. In terms of fracture behaviour, ductile dimples, cleavage facets and cracks passing through lamellar structures were observed in all samples. However, the quantity of these fracture features varied significantly in each sample.
\end{abstract}

\section{Introduction}

Titanium parts produced by conventional powder metallurgical (PM) routes generally contain residual pores that lead to inferior mechanical properties compared to corresponding ingot materials. Therefore, employment of additional secondary processes is essential for fully consolidating the material. Direct powder consolidation by thermo-mechanical powder processing such as PCE has a potential to provide fully dense material with a minimum of processing steps. PCE combines traditional PM and conventional extrusion technology along with the derived benefits of both processes. In PCE processing, the first key step prior to pressing is the blending or mixing of the titanium powder with master alloys or individual alloy powders to ensure a homogeneous distribution of particles and composition. The next step is compaction to form a cylindrical green compact, which is then heated in a controlled atmosphere to consolidate the green compact. Finally, extruding the sintered compact reduces the porosity and gives the desired shape and properties required for specific applications.

The mechanical properties (particularly tensile properties) of PCE produced titanium alloys are well documented in a recent article by Gabbitas et. al [1]. Typical un-optimised tensile properties of Ti$6 \mathrm{Al}-4 \mathrm{~V}$ alloy produced by vacuum sintering plus extrusion along with properties from ingotproduced material are shown in Table 1 . Ti-6Al-4V alloy produced by PCE has a low ductility 
compared with wrought material. A major reason for brittle behaviour might be because of unoptimised processing or higher oxygen levels in the powder material compared with wrought material. Therefore, further optimisation of processing conditions as well as some reduction in oxygen content is essential to improve ductility while retaining good strength levels.

Table 1: Typical un-optimised tensile properties of Ti-6Al-4V alloy produced by powder compact extrusion (along with ingot produced material)

\begin{tabular}{|c|c|c|c|c|c|}
\hline $\begin{array}{c}\text { Process } \\
\text { Type }\end{array}$ & $\begin{array}{c}\text { 0.2\% Yield Strength } \\
{[\mathrm{MPa}]}\end{array}$ & $\begin{array}{c}\text { Ultimate Tensile Strength } \\
{[\mathrm{MPa}]}\end{array}$ & $\begin{array}{c}\text { Elongation } \\
{[\%]}\end{array}$ & $\begin{array}{c}\mathrm{O}_{2} \\
{[\mathrm{wt.} \%]}\end{array}$ & Ref. \\
\hline Wrought & 827 & 896 & $10-14$ & 0.20 & {$[2]$} \\
\hline PCE & $790-1130$ & $886-1245$ & $1.2-4.5$ & $0.40-0.50$ & {$[3,4]$} \\
\hline
\end{tabular}

In addition, impact properties of PM materials are important and yet this aspect of PM Ti-6Al-4V has received little attention or comment in the literature. This provides the theme for the current study. Factors investigated include: processing, microstructure, performance under high strain rate and tri-axial stress state, and fracture behaviour of PCE produced Ti-6Al-4V alloy. To understand the effect of oxygen on impact toughness, this study used two starting titanium powders with different impurity levels to produce testing feedstock.

\section{Experimental Procedure}

A Ti-6Al-4V alloy composition was obtained by blending 9:1 weight ratio of elemental HDH titanium powder and master alloy powder (MA 60Al-40V). Two batches of HDH titanium powders (batch 1 and batch 2) with different oxygen contents were used as starting materials. The measured oxygen contents and particle size of these starting powders are presented in Table 2.

Table 2: Oxygen content and particle size of starting materials

\begin{tabular}{|c|c|c|c|c|c|c|}
\hline \multicolumn{2}{|c|}{ Starting Powders } & $\begin{array}{c}\text { Oxygen } \\
\text { content }\end{array}$ & \multicolumn{2}{c|}{ Volume Fraction Below Particular $\mu m$} & \multirow{2}{*}{$\begin{array}{c}\text { Particle } \\
\text { Size }\end{array}$} \\
\hline \multirow{2}{*}{ Type } & Batch & {$[w t . \%]$} & $D[0.1]$ & $D[0.5]$ & $D[0.9]$ & \\
\hline \multirow{2}{*}{ HDH Ti } & 1 & $0.31-0.33$ & 20.8 & 47.6 & 90.8 & -200 mesh \\
\cline { 2 - 6 } & 2 & $0.23-0.25$ & 27.0 & 51.3 & 89.5 & -200 mesh \\
\hline MA (60Al40V) & - & 0.61 & 28.4 & 53.5 & 91.2 & -250 mesh \\
\hline
\end{tabular}

The idea of using two different starting HDH titanium powders was to produce extruded rods with variable oxygen contents. For a single mixing, $500 \mathrm{~g}$ of raw powder mixture was added to an airtight plastic container along with stainless steel balls (added 2:1 weight ratio to powder). A roller mill was used to rotate this container at an approximate speed of $200 \mathrm{rpm}$ for 24 hours. Once the mixing cycle had finished, the powder mixture was sieved to remove the stainless steel balls. It was then used to produce a green powder compact by uniaxial warm compaction. The blended powder mixture was poured into a $56 \mathrm{~mm}$ diameter steel die. The inner surface of this die and plunger had been coated with colloidal graphite lubricant to reduce die wall friction. Heating of the die to $220^{\circ} \mathrm{C}$ was achieved using a band heater in air and temperature was monitored using a thermo-couple. Once the desired temperature was reached, a uni-axial pressure in the range of 310-330 MPa was applied using a 100-ton hydraulic press for eight minutes. The resulting cylindrical compact ejected from the die was $60 \mathrm{~mm}$ high and had a relative green density in the range of $80-85 \%$. To perform the final extrusion step in air these compacts had to have further consolidation using vacuum sintering (to get relative density to $\sim 93 \%$ ). The sintering of green compacts was performed at $1325^{\circ} \mathrm{C}$ with a heating rate $10^{\circ} \mathrm{C} / \mathrm{min}$. The isothermal hold time was selected to be two hours 
followed by natural furnace cooling to room temperature. A high vacuum, in the range of $1-3 \times 10^{-2}$ $\mathrm{Pa}$, was applied in furnace chamber during heating and isothermal holding. For hot extrusion, vacuum sintered compacts were heated to temperatures in the range of $1150 \sim 1200^{\circ} \mathrm{C}$ using an induction coil in air. The hot compact was manually shifted to a cylindrical extrusion chamber which, along with the appropriate die, was already at $420^{\circ} \mathrm{C}$. The ram of a 300 ton hydraulic press was used to push the material through a $20 \mathrm{~mm}$ diameter extrusion die (extrusion ratio of 9:1) at a speed of $122 \mathrm{~mm} / \mathrm{s}$.

The material characteristics such as actual chemical composition and oxygen contents of the processed material were obtained by X-ray fluorescence (XRF), inert gas fusion method. The microstructures of as-vacuum sintered and as-extruded material were observed using an optical microscope (Olympus BX60) and a scanning electron microscope (SEM) (Hitachi S4000). The ground and polished samples for optical and SEM were etched in a modified Kroll's reagent consisting of 2 vol. $\% \mathrm{HF}, 4$ vol. $\% \mathrm{HNO}_{3}$ and 94 vol. $\% \mathrm{H}_{2} \mathrm{O}$. The optical micrographs captured at different magnifications were used to manually estimate (using Image ${ }^{\circledR}$ ) the microstructural features such as prior $\beta$ grain size, colony size, thickness of $\alpha$ lamellas and grain boundary $\alpha$. To incorporate the effect of orientation on each microstructural feature, half of the data was collected on longitudinal micrographs and the other half was obtained from transverse micrographs. An intercept method was used to measure a minimum of 100 grains and 200 colonies per sample. The mean lineal intercept length attained by this method was used as a direct estimation of prior $\beta$ grain size and colony scale factor (mean colony size). Similarly, at least $200 \alpha$ lamellae and 25 grain boundary $\alpha$ measurements per sample were collected to get the mean thickness.

To obtain high strain rate performance data for the material under a tri-axial stress state, standard Charpy impact specimens with dimensions $10 \mathrm{~mm}$ x $10 \mathrm{~mm}$ x $55 \mathrm{~mm}$ were machined and a $2 \mathrm{~mm}$ deep v-notch (with approximate tip radius of $0.25 \mathrm{~mm}$ ) was introduced as specified in the ASTM standard E23-07. Impact testing was performed at room temperature using an Avery-6703 impact tester with a maximum energy rating of $300 \mathrm{~J}$, impact velocity of $5 \mathrm{~m} / \mathrm{s}$ and a margin of error of \pm 2 J. The fracture surfaces of impacted specimens were examined using a Zeiss Evo MA25 SEM.

\section{Results and Discussion}

A summary of the material produced during this current study is shown in Table 3. The labelling of the samples in the current study is based on processing history and it should be noted that samples VS-E1 and VS-E2 were prepared as a single batch, before the processing of VS-E3. Sample VS-E1 was prepared using high oxygen (0.31-0.33 wt.\%) batch $1 \mathrm{HDH}$ titanium powder and the other two rods were produced from batch 2 . Commercially available Ti-6Al-4V alloy produced by ingot/wrought methods has a composition in the range 5.5-6.75 wt.\% $\mathrm{Al}, 3.5-4.5 \mathrm{wt} . \% \mathrm{~V}$ and the balance is titanium [5]. The chemical composition of the as-extruded rods in this current study is in agreement with the above values.

Table 3: Summary of the as-extruded Ti-6Al-4V rods produced by PCE using a powder mixture

\begin{tabular}{|c|c|c|c|c|c|c|}
\hline \multirow{2}{*}{ Sample Name } & \multirow{2}{*}{$\begin{array}{c}\mathrm{HDH} \mathrm{Ti} \\
\text { Batch }\end{array}$} & \multirow{2}{*}{ Extrusion Ratio } & \multicolumn{4}{|c|}{ Composition [wt.\%] } \\
\cline { 5 - 7 } & & & $T i$ & $A l$ & $V$ & $O$ \\
\hline VS-E1" & Batch 1 $^{+}$ & \multirow{3}{*}{$9: 1$} & 90.3 & 5.9 & 3.7 & 0.47 \\
\hline VS-E2 & \multirow{2}{*}{ Batch 2 $^{++}$} & & 90.6 & 5.7 & 3.6 & 0.41 \\
\hline VS-E3 & & & 90.5 & 5.8 & 3.6 & 0.34 \\
\hline
\end{tabular}

Note: VS-E1": Vacuum Sintered and Extruded rod one. Batch $1^{+}$: oxygen content of starting HDH powder was $0.31-0.33$ wt $\%$ and addition of master alloy has provided 0.38 wt.\% oxygen for the powder mixture. Batch $2^{++}$: oxygen content of starting HDH powder was $0.23-0.25 \mathrm{wt} \%$ and addition of master alloy has provided $0.28 \mathrm{wt} \%$ oxygen for the powder mixture. 
Oxygen Contents: The oxygen content of all extruded rods produced was higher than that for typical commercially available ingot Ti-6Al-4V alloy [5]. Those samples prepared as part of the initial batch clearly show variable amounts of oxygen pick-up during processing (Figure 1). Overall, the amount of oxygen pickup for VS-E1, and VS-E2 samples during the entire processing (warm pressing, vacuum sintering and final heating and extrusion in air) was around $0.11-0.13 \mathrm{wt} . \%$. There are many possible reasons that could contribute to increased oxygen content of VS-E2 (processed as part of the initial batch) in comparison to VS-E3, despite the fact that both of these samples were prepared from the same batch of powder. During the processing of VS-E2, it was observed that after warm compaction, the ejection of the compact was difficult. This particular observation caused uncertainty about compact integrity, as uneven pressure distribution during the ejection process may have caused internal cracking or the formation of large pores/voids within the compact. During sintering or induction heating these defects, along with open surface pores, might have created a pathway for oxygen or other impurities pickup.

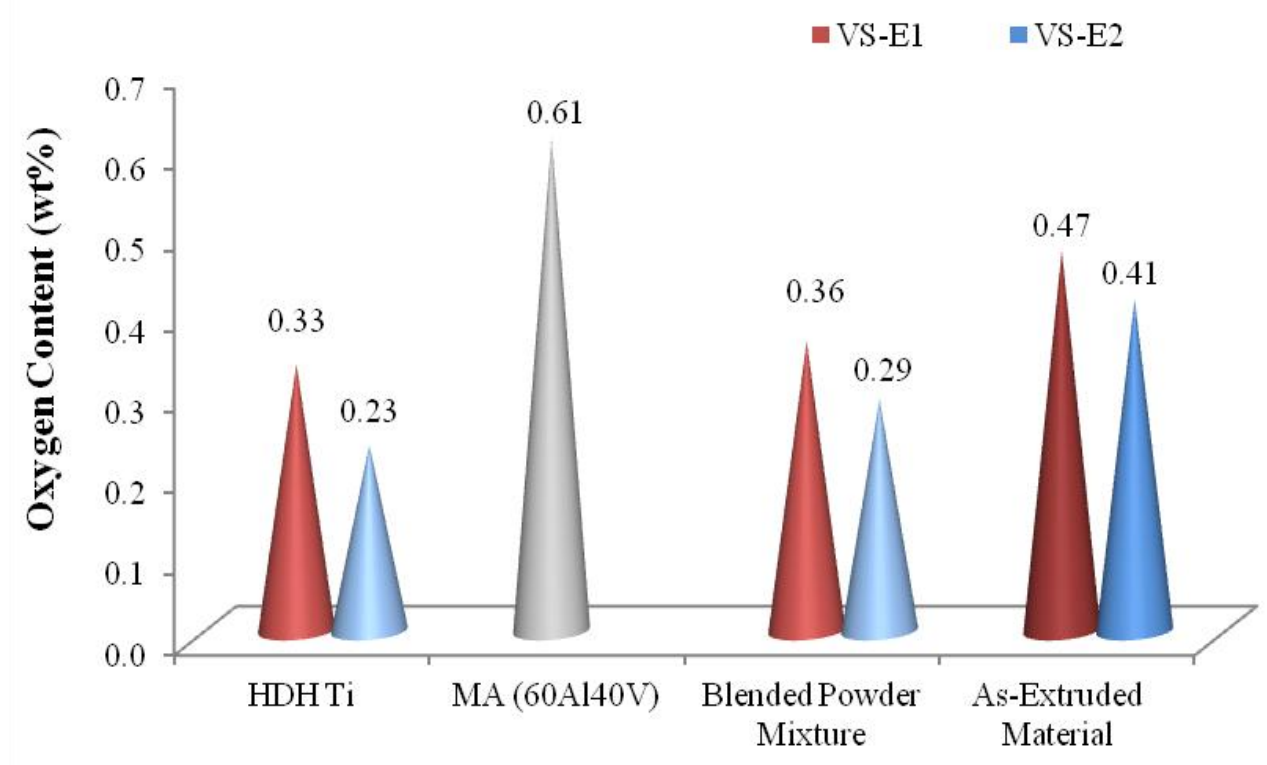

Figure 1: Oxygen contents of individual powders, powder mixture and various as-extruded rods

Sample VS-E3 had an oxygen content that most closely matched (only $0.04 \mathrm{wt} \%$ higher) the specification stated in ASTM-B988 standard for powder produced structural components. According to this standard, the oxygen content in the final powder produced component cannot exceed $0.30 \mathrm{wt} . \%$. In the current study, batch $1 \mathrm{HDH}$ starting powder had higher oxygen content than in the specification. Therefore, to achieve an acceptable level of impurity in the final product it is very important that starting powders should have low oxygen contents. However, producing or sourcing high quality $\mathrm{HDH}$ powder is not only challenging, but it also influences the cost effectiveness of the overall process.

Figure 2 provides sufficient evidence that starting powders were the major contributor for the oxygen levels obtained in as-extruded rods. In the case of the VS-E3 sample, the starting HDH titanium powder contributes $66 \%$ of the oxygen present in the final extruded rod. This value is approximately four times higher than the actual oxygen pickup during the entire processing. Similarly, the relative contribution from the master alloy is around $18 \%$, which is slightly higher than the oxygen pick-up during the entire process. Also, based on the proportion of master alloy in a blended powder mixture, this value was significantly higher compared to the relative contribution from HDH titanium powder. It should be noted that, Figure 2 is constructed by measuring the oxygen content of HDH titanium powder, master alloy powder and as-extruded rod. The oxygen content of the blended powder mixture was not measured due to technical limitations and instead theoretically calculated values based on the proportion of two powders were used. 

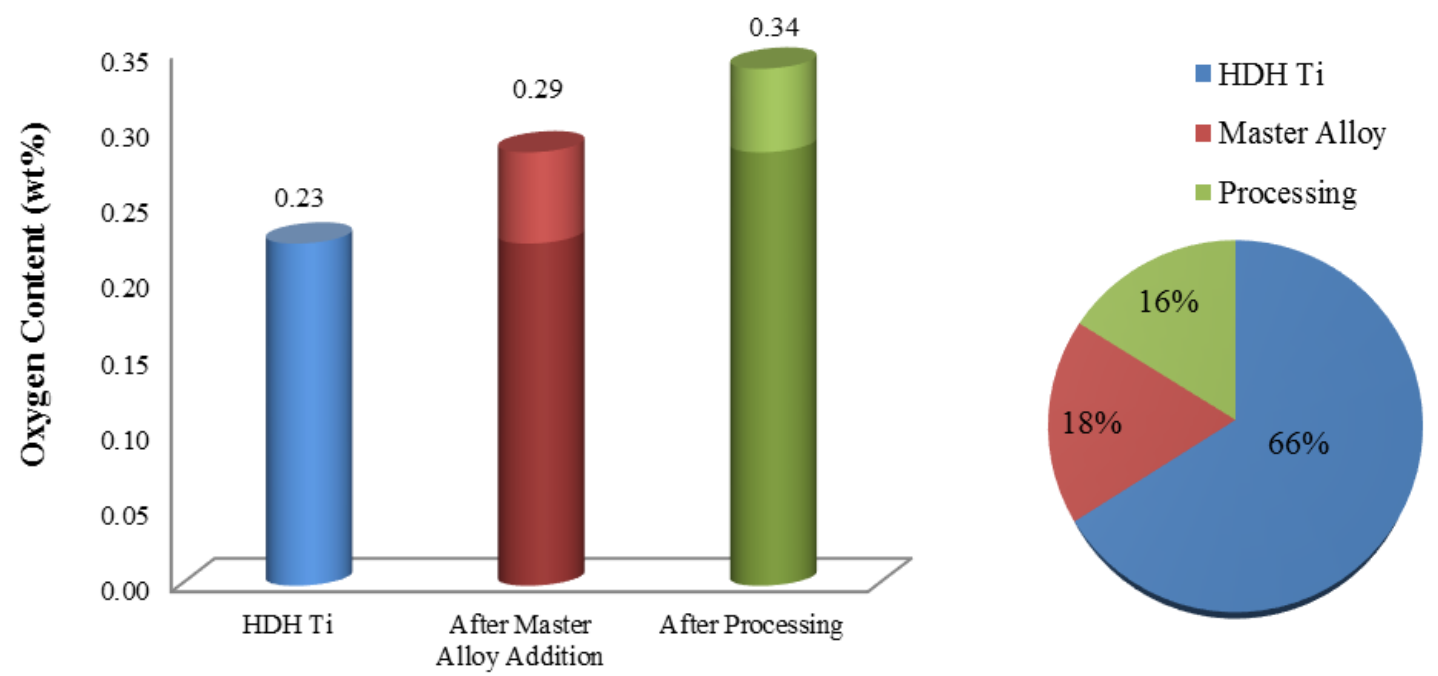

Figure 2: Source of oxygen and oxygen pickup during processing of VS-E3 Sample.

Microstructure: Typical optical micrographs from longitudinal and transverse cross-sections of a Ti-6Al-4V compact after vacuum sintering at $1325^{\circ} \mathrm{C}$ for $120 \mathrm{~min}$ are shown in Figure $3(\mathrm{a}-\mathrm{b})$. The as-sintered powder compact has a fully lamellar microstructure. The $\alpha$ phase has a lighter grey appearance, which is transformed from the $\beta$ phase by nucleation and growth during slow furnace cooling after sintering. The $\beta$ phase has a darker appearance, which delineates the lamellae colonies with different orientation angles. In addition to these microstructural features, a small number of pores are also present. Based on their shape, size and location, these pores can be divided into two categories; small near-circular shaped pores that are present inside a grain and larger lenticular pores present on the grain boundaries.
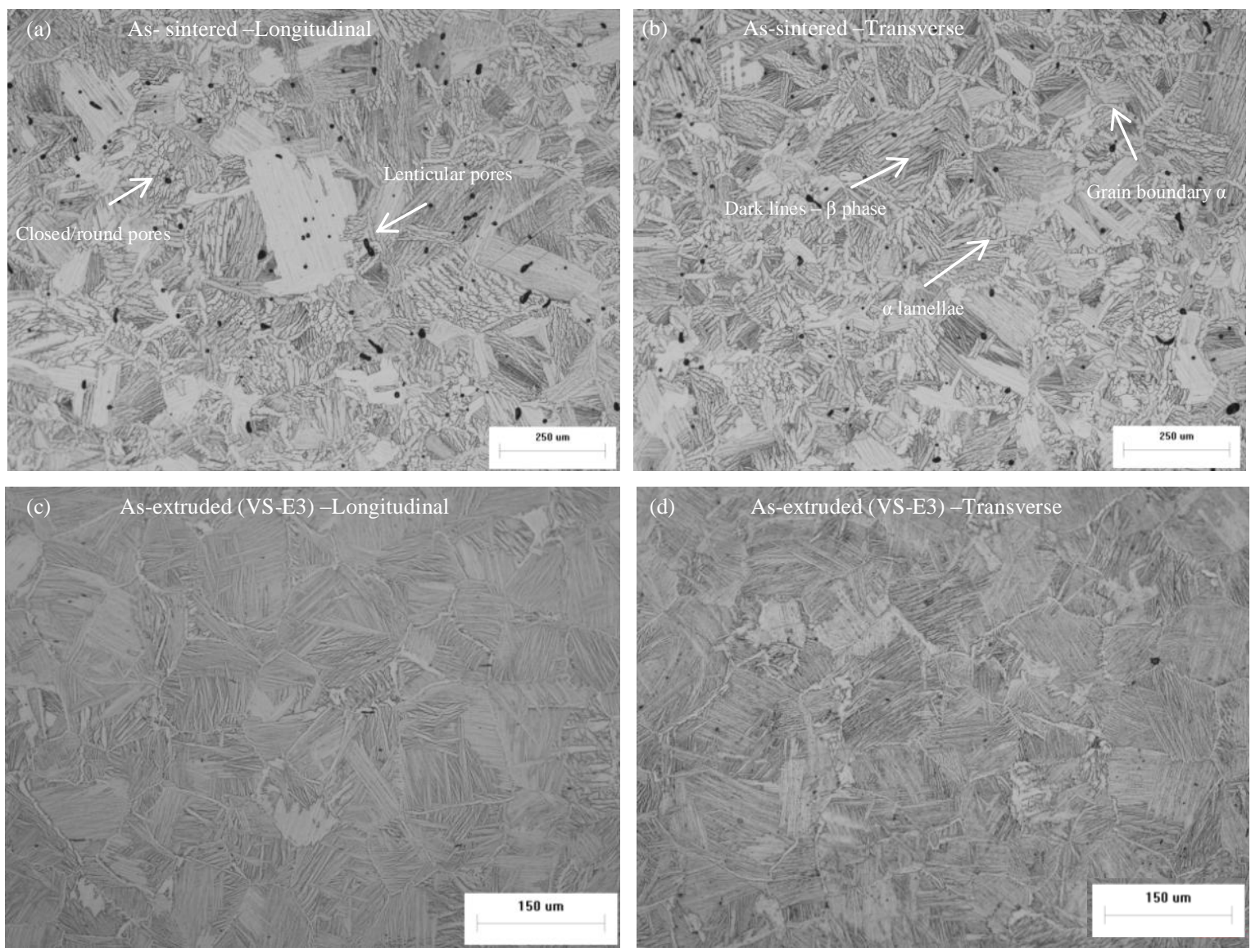

Figure 3: Optical micrographs of longitudinal and transverse cross-sections: (a-b) as-sintered Ti6Al-4V alloy and (c-d) as-extruded VS-E3 specimen 
The results attained from optical micrographs processed by Image J, suggest that the evolution of microstructural features during hot extrusion created drastic changes compared to as-sintered material (Table 4). The morphology of the microstructure in as-extruded (VS-E3) is lamellar or Widmanstätten. However, severe deformation during extrusion has given rise to significant grain refinement along with elimination of most of the pores as shown in Figure 3 (c-d). The microstructure after extrusion clearly shows a 70-80\% reduction in the thickness of the $\alpha$ laths and grain boundary $\alpha$.

Table 4: Estimated size of the microstructural features for as-sintered and as-extruded material

\begin{tabular}{|c|c|c|c|c|c|}
\hline \multirow{2}{*}{ Sample } & Orientation & $\begin{array}{c}\text { Mean Lineal Intercept } \\
\text { Length }[\mu \mathrm{m}]\end{array}$ & $\begin{array}{c}\text { Colony Scale } \\
\text { Factor }[\mu \mathrm{m}]\end{array}$ & $\begin{array}{c}\text { Thickness of } \\
\text { a lath }[\mu \mathrm{m}]\end{array}$ & $\begin{array}{c}\text { Thickness of Grain } \\
\text { Boundary } \alpha[\mu \mathrm{m}]\end{array}$ \\
\hline \multirow{2}{*}{ VS } & Longitude & $152 \pm 17$ & $90 \pm 6$ & $9.3 \pm 1$ & $11.2 \pm 0.7$ \\
\cline { 2 - 6 } & Transverse & $163 \pm 6$ & $71 \pm 2$ & $9.1 \pm 1$ & $11.3 \pm 0.4$ \\
\hline \multirow{2}{*}{ VS-E3 } & Longitude & $104 \pm 6$ & $46 \pm 3$ & $1.8 \pm 0.1$ & $3.3 \pm 0.8$ \\
\cline { 2 - 6 } & Transverse & $92 \pm 4$ & $60 \pm 3$ & $1.8 \pm 0.2$ & $2.6 \pm 0.1$ \\
\hline
\end{tabular}

A comparison of longitudinal and transverse cross-sections from sample VS-E3 clearly suggests that the structure of the $\alpha$ laths and the grain boundary $\alpha$ are consistent. However, there is some variation in the grain and colony size due to an orientation effect. The value of mean linear intercept length (estimated grain size) measured on a longitudinal cross-section suggests that the grains present here are elongated compared to those in the transverse direction. This is expected as supplementary deformation in the extrusion direction gives rise to lengthened grains. The above order is reversed for the colony scale factor (an estimation of colony size).

Generally, during severe deformation it is easy to eliminate most of the closed pores present in a sintered compact. However, defects deriving from the green state, along with open pores or some lenticular pores present after sintering, act as oxygen absorbing pathways. The pores and other defects also contaminate the sample by forming an oxidised internal surface layer. These contaminated surfaces do not completely merge during extrusion and appear as micro-cracks in the as-extruded microstructure [3]. This has happened in samples VS-E1 and VS-E2 and as a result there has been high oxygen pick-up during processing. The presence of micro-cracks in these samples can be easily visualised under back-scattered electron (BSE) imaging mode of SEM (see Figure 4 (c and d)). Observation of larger cross sectional areas for VS-E3 sample shows that the size and quantity of micro-cracks present in this particular case was significantly small compared to other two. Therefore, it is expected that mechanical performance of this specific rod should be superior.
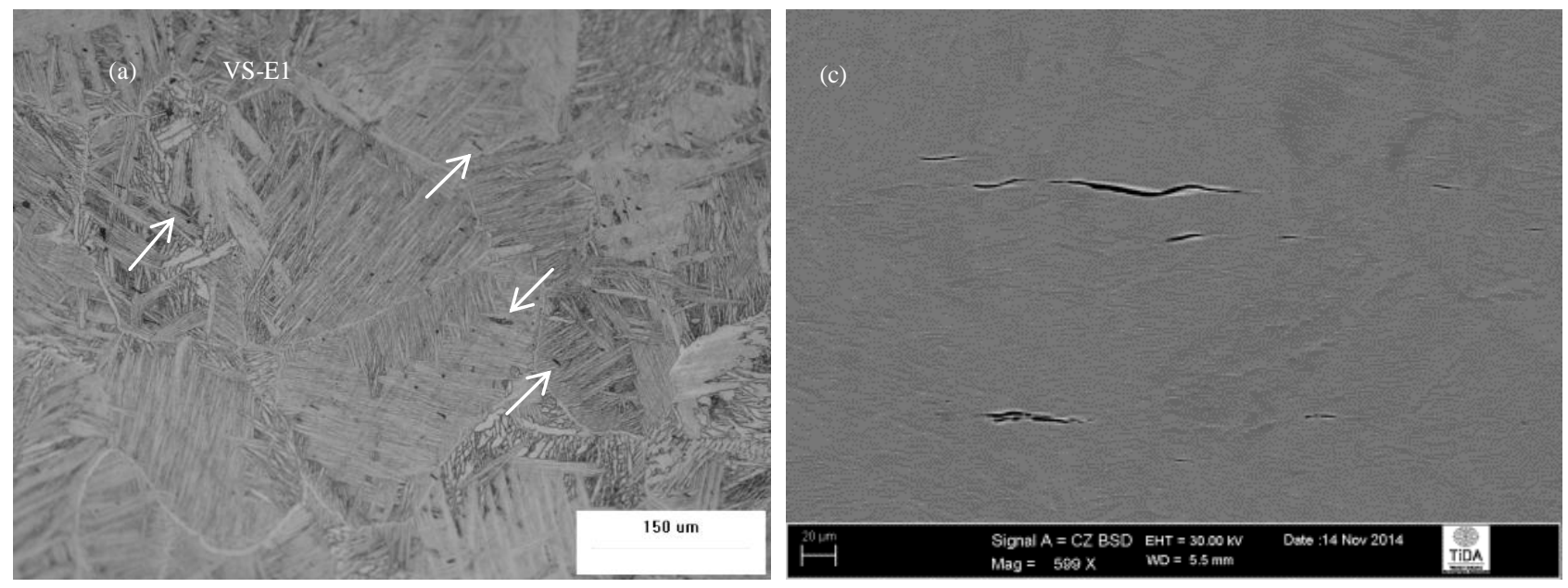

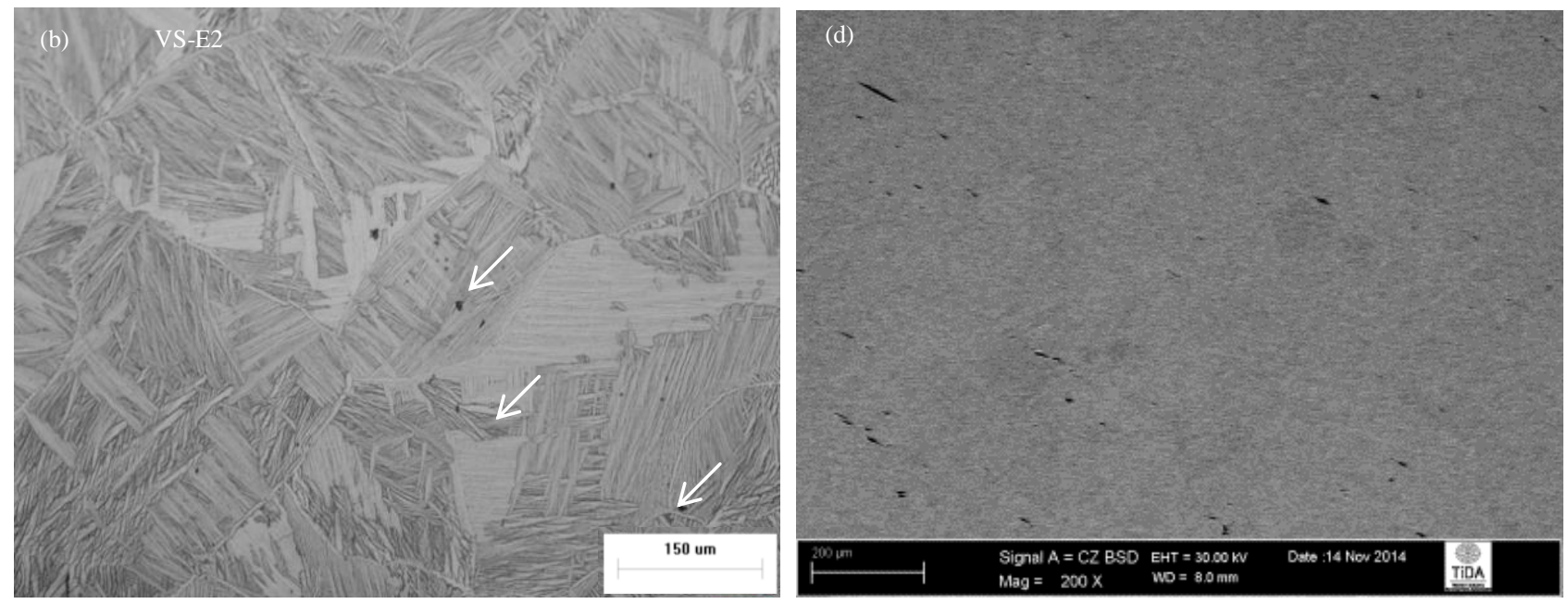

Figure 4: (a-b) Optical micrographs and (c-d) Back Scattered Electron (BSE) images showing longitudinal cross section of as-extruded Ti-6Al-4V rods VS-E1 and VS-E2.

Impact Toughness: The results of v-notch Charpy impact tests show that specimen VS-E3 absorbs $14 \mathrm{~J}$ of energy to fracture compared to the other two samples that exhibit impact toughness of 10$10.5 \mathrm{~J}$. For VS-E1 and VS-E2 only two specimens per test were used due to limited length of extruded rods, whereas VS-E3 had three replicates. There is a clear indication that impact toughness improves as the oxygen content of the extruded sample decreases (see Figure 5). Sample VS-E1 with an oxygen content of $0.47 \mathrm{wt} . \%$, absorbs $10 \mathrm{~J}$ of energy before failure. This impact energy value is approximately $30 \%$ less than VS-E3 that has an oxygen content of $0.34 \mathrm{wt} . \%$. Therefore, a decrease in oxygen content of 0.13 wt.\% results in an improvement of $4 \mathrm{~J}$ in the materials energy absorbing capacity. Other than this, Figure 5 also suggests that the change in impact toughness for oxygen contents greater than $0.4 \mathrm{wt} . \%$ is minimal. However further work is underway to obtain a trend showing the change in impact toughness with respect to increases in oxygen content.

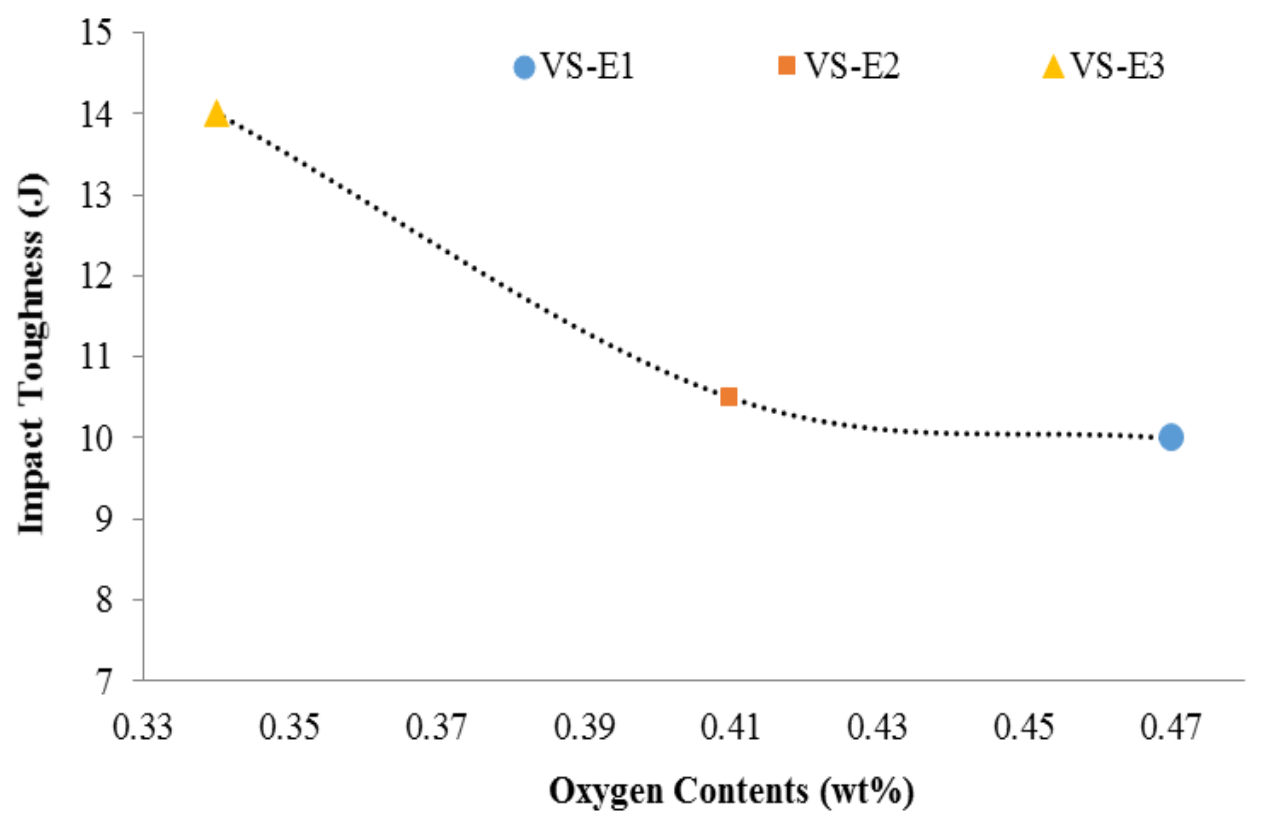

Figure 5: Relation between impact toughness and oxygen contents of as-extruded Ti-6Al-4V alloy

For comparison, impact toughness data given in the literature for a Ti-6Al-4V alloy is shown in Figure 6. It is evident that the best impact toughness attained in this current work is lower than impact toughness values reported in the literature except in the case of as-cast and Selective Laser Melted (SLM) Ti-6Al-4V material [5-12]. No study has been found in the literature, which provides impact data for Ti-6Al-4V produced by PCE processes or a similar production method. Therefore, a 
broad-spectrum of impact energy values are included in this section for comparing different production methods.



Figure 6: Comparison of impact toughness attained for PCE produced Ti-6Al-4V alloy with literature data present on various methods [5-12].

The main reasons for the differences between impact values given in the literature and the results from this study are: a higher oxygen content and the form of the microstructure attained after PCE processing. The oxygen content of test-pieces used in the literature was $\leq 0.2 \mathrm{wt} . \%$, which is significantly lower than the oxygen content of samples VS-E1, VS-E2 and VS-E3 [5,8-12]. It is clear from the literature, that the presence of oxygen is favourable for some properties whereas it is detrimental for others [2,13]. Generally, high oxygen content in the titanium lattice increases the yield strength, ultimate tensile strength, Young's modulus, fatigue strength and hardness, but compromises the ductility, impact strength and fracture toughness.

Other than oxygen content, microstructural features along with the presence of micro-cracks have a significant effect on impact behaviour and it should be realized that ingot metallurgy and PM techniques such as HIPing of PREP powders would give rise to very different microstructural features. Therefore, based on this general comparison with various studies from the literature, no conclusive comment can be made about the main reason for low impact toughness, as it could be purely due to the difference in oxygen content or due to variations in microstructure (particularly the presence of micro-cracks which can act as stress concentrators). Therefore, further work is underway to explore the effect of various microstructures and oxygen contents on impact toughness.

Fracture Behaviour: The fracture surfaces of impact specimen VS-E3 have rough and irregular appearance at low magnification as shown in Figure 7 (a). This irregularity indicates that cracks were deflected significantly during propagation to achieve a least energy consumption path. The frequent change in crack path is a beneficial phenomenon, because it simply highlights the fact that cracks have to do a large amount of work to propagate and break a specimen into two halves. In other words, a lamellar type microstructure has provided significant resistance to crack propagation. Figure 7 (c-d) shows high magnification fractographs that contain a significant amount of cleavage facets along with large plane spallings (or transgranular features). Meyer et al. have linked the 
formation of these large spallings to the crack travelling along lamellae interfaces [14]. To prove that the same phenomenon is occurring here, a detailed investigation of crack path is in progress.
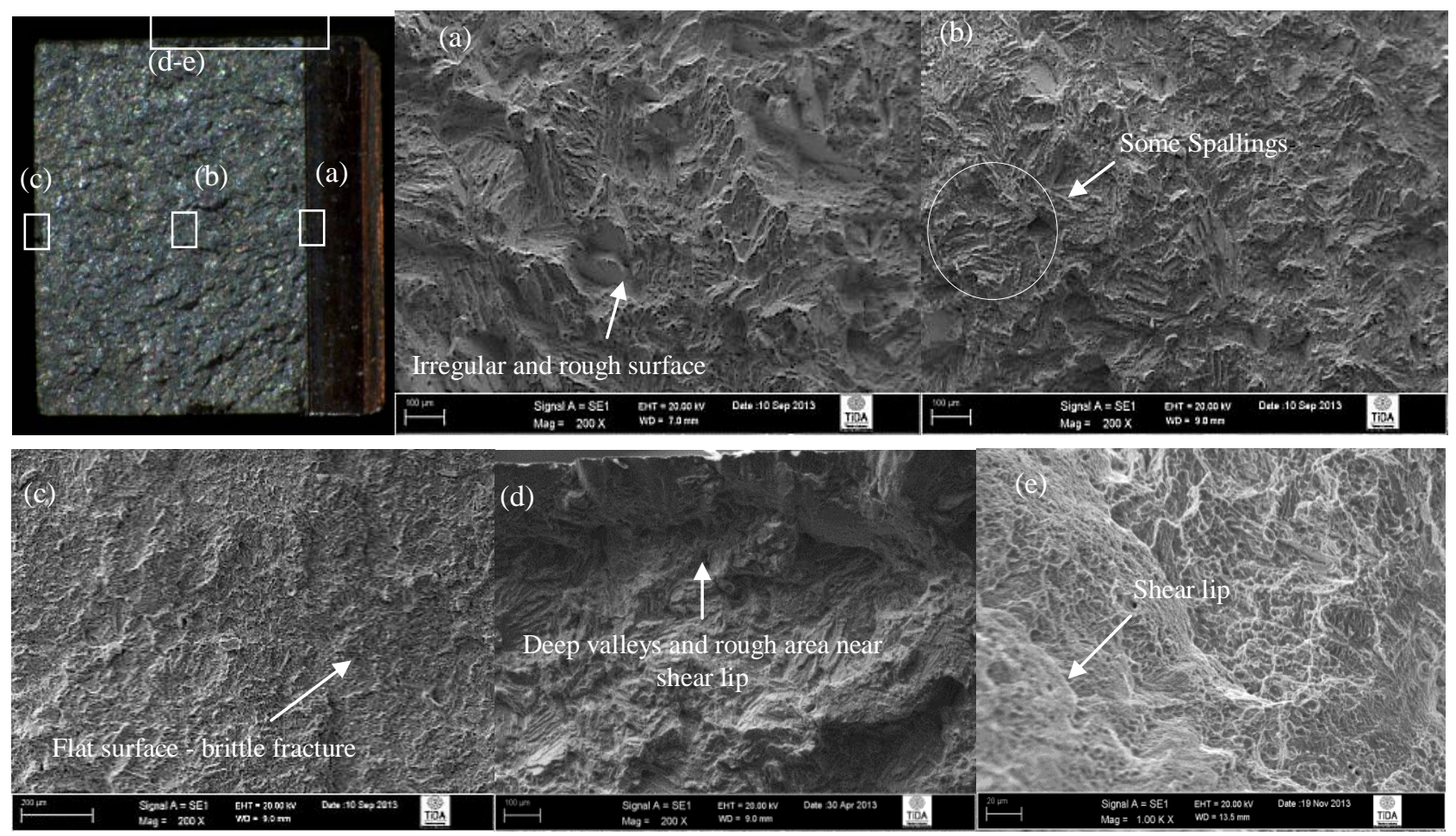

Figure 7: Typical fractographs of Charpy impact specimens (a) near the notch (b) centre (c) side opposite to the notch (d-e) shear lip.

A limited amount of ductile fracture is displayed in Figure 7 (d-e) in the form of a thin shear lip and tiny ductile dimples that were distributed throughout the fracture surface, particularly near the shear lip area that contains a relatively high quantity of fine dimples. Overall, the fracture area containing ductile dimples and shear lips was significantly lower than the area represented by cleavage and trans-granular fracture in all surfaces investigated. Hence, it was very evident that brittle fracture was the predominant mode of failure.

\section{Summary}

In this study, a blended powder mixture of Ti-6Al-4V alloy was successfully consolidated using powder compact extrusion. The idea of systematically changing oxygen content by using different starting titanium powders had limited success, as there was variability in the degree of oxygen pickup in some samples during processing. The severe deformation during extrusion had a significant effect on lamellar type in the as-sintered microstructure. The impact toughness of asextruded Ti-6Al-4V rods was found to be between 10-14 J, which is lower than material produced by ingot metallurgy and other PM routes. The high oxygen content and un-optimised microstructure was thought to be the potential reason for inferior impact properties of the material produced in this study. On the whole, this study illustrates that thermomechanical powder metallurgy (TPM) processes like powder compact extrusion are very attractive and have great potential for producing high-quality near-net shaped products with a wide range of compositions, microstructures and mechanical properties.

\section{Acknowledgements}

The funding from the Ministry of Business, Innovation and Employment (MBIE), New Zealand to support this work is gratefully acknowledged. The authors also express sincere thanks to the 
Titanium Industry Development Association (TiDA, Tauranga, New Zealand) for providing technical support for this research study.

\section{References}

[1] B. Gabbitas, F. Yang, S. Raynova, M.T. Jia, Cost effective forging of titanium alloy parts and their mechanical properties, in: Advanced Materials Research Trans Tech Publ, 2014, pp 3-10.

[2] M.J. Donachie, Titanium: A Technical Guide, 2 ed., ASM International, 2000.

[3] F. Yang, B. Gabbitas, A. Mukhtar, W. Downing, Preparation of titanium alloy rods by powder compact extrusion, in: Advanced Materials Research Trans Tech Publ, 2014, pp 241-247.

[4] F. Yang, D.L. Zhang, H.Y. Lu, B. Gabbitas, Preparation, microstructure and properties of Ti$6 \mathrm{Al}-4 \mathrm{~V}$ rods by powder compact extrusion of powder mixture in: M. Qian (Ed.), Powder Metallurgy of Titanium: Powder Processing, Consolidation and Metallurgy of Titanium, 2012, pp 70-75.

[5] Information on http://asm.matweb.com/search/SpecificMaterial.asp?bassnum=MTP641

[6] A.P. Singh, B. Gabbitas, F. Yang, R. Torrens, A. Mukhtar, Effect of pre-consolidation methods and oxygen on the mechanical properties of as-extruded Ti-6Al-4V alloy rods, Presented at Ti-2015: The 13th World Conference on Titanium, Manchester Grand Hyatt * San Diego, California, August 16-20, 2015.

[7] Impact properties of titanium and $\mathrm{Ti}-6 \mathrm{Al}-4 \mathrm{~V}$ produced by powder compact forging and extrusion Unpublished report, Waikato Centre for Advance Materials, School of Engineering, University of Waikato, Hamilton, New Zealand, 2011.

[8] E. Collings, Materials Properties Handbook: Titanium Alloys, Asm Intl, 1994.

[9] Information on http://rtiintl.s3.amazonaws.com/RTI-Reports/tiguideWeb.pdf

[10] R. Reda, A. Nofal, A.-H. Hussein, Effect of single and duplex stage heat treatment on the microstructure and mechanical properties of cast Ti-6Al-4V alloy, Metallography, Microstructure, and Analysis 2 (2013) 388-393.

[11] S. Zherebtsov, E. Kudryavtsev, S. Kostjuchenko, S. Malysheva, G. Salishchev, Strength and ductility-related properties of ultrafine grained two-phase titanium alloy produced by warm multiaxial forging, Materials Science and Engineering a-Structural Materials Properties Microstructure and Processing 536 (2012) 190-196.

[12] E. Yasa, J. Deckers, J.P. Kruth, M. Rombouts, J. Luyten, Experimental investigation of Charpy impact tests on metallic SLM parts, in: Innovative Developments in Design and Manufacturing: Advanced Research in Virtual and Rapid Prototyping CRC, Boca Raton, FL, 2010, pp 207-214.

[13] A.P. Singh, B. Gabbitas, D.L. Zhang, Fracture toughness of powder metallurgy and ingot titanium alloys - a review, in: M.A. Imam, F.H.S. Froes, R.G. Reddy (Eds.), Key Engineering Materials , vol. 551: Cost-Affordable Titanium IV Trans Tech Publications, Durnten-Zurich, 2013, pp 143-160.

[14] L.W. Meyer, L. Krüger, K. Sommer, T. Halle, M. Hockauf, Dynamic strength and failure behavior of titanium alloy Ti-6Al-4V for a variation of heat treatments, Mechanics of TimeDependent Materials 12 (2008) 237-247. 